\title{
An Evaluation of the Nitric Oxide/cGMP/cGMP-Dependent Protein Kinase Cascade in the Induction of Cerebellar Long-Term Depression In Culture
}

\author{
David J. Linden, ${ }^{1}$ Ted. M. Dawson, ${ }^{1,2}$ and Valina L. Dawson ${ }^{2,3}$ \\ Departments of ${ }^{1}$ Neuroscience, ${ }^{2}$ Neurology, and ${ }^{3}$ Physiology, The Johns Hopkins University School of Medicine, \\ Baltimore, Maryland 21205
}

\begin{abstract}
Cerebellar long-term depression (LTD) is a model system of information storage in which a persistent attenuation of the parallel fiber-Purkinje neuron (PN) synapse is induced by conjunctive stimulation of parallel fiber and climbing fiber inputs at low frequency. As some studies have suggested that release of the gaseous second messenger, nitric oxide (NO), in the molecular layer and the consequent activation of soluble guanylate cyclase and cGMP-dependent protein kinase (PKG) in the PN, is necessary for LTD induction, we have further examined this hypothesis using a cell culture protocol. In cerebellar cultures made from transgenic mice in which the gene for neuronal nitric oxide synthase (nNOS) has been rendered null, LTD induced by glutamate/depolarization conjunctive stimulation was indistinguishable from that in cultures from wild-type mice in terms of amplitude, rate of onset, and duration. Bath application of CGMP analogs produced a large $(80 \%)$, transient attenuation of glutamate-gated inward currents. However, application of an activator of soluble guanylate cyclase or an inhibitor of type V cGMP-phosphodiesterase did not mimic the effect of cGMP analogs, and inclusion of cGMP analogs in the patch pipette did not give rise to a slowly developing attenuation, suggesting that these compounds exert their effects at the cell surface. Free $\mathrm{Ca}$ was measured in the distal dendritlc arbor of single PNs by fura-2 microfluorimetry. Cyclic ADP-ribose (cADPr), which has been suggested to be formed by a CGMP/PKG-dependent process and to be an endogenous ligand of the type 2 ryanodine receptor, increased the response to a $3 \mathrm{sec}$ depolarizing step from -80 to $+10 \mathrm{mV}$ when included in the patch pipette. This effect was completely antagonized by the co-inclusion of a competitive inhibitor $\left(8-\mathrm{NH}_{2}-\right.$ cADPr). Induction of LTD was not blocked by inclusion in
\end{abstract}

\footnotetext{
Received Jan. 12, 1995; revised Mar. 13, 1995; accepted Mar. 15, 1995.

Ms. Dorit Gurfel provided skillful technical assistance. Dr. T. Walseth synthesized cADPr and 8- $\mathrm{NH}_{2}-\mathrm{CADPr}$ and kindly provided them for this investigation. Drs. U. Walter and P. De Camilli generously donated antiserum to PKG. Drs. S. Vincent and T. Walseth provided useful comments on an earlier version of this manuscript. This work was supported by PHS Grant MH51106, a Klingenstein Fellowship, an Alfred P. Sloan Research Fellowship, and a McKnight Scholarship to D.J.L. T.M.D. is supported by Public Health Service Gran NS05178, the American Health Assistance Foundation and the International Life Science Institute. V.L.D. is supported by the American Foundation for AIDS Research, Alzheimer's Association, National Alliance for Research on Schizophrenia and Depression, and the American Heart Association.

Correspondence should be addressed to David J. Linden, Department of Neuroscience, The Johns Hopkins University School of Medicine, 725 North Wolfe Street, Baltimure, MD 21205.

Copyright $(1995$ Society for Neuroscience $0270-6474 / 95 / 155098-08 \$ 05.00 / 0$
}

the patch pipette of three different PKG inhibitors or 8-NH2CADPr. These results suggest that while cGMP/CADPr signaling may be important in neuronal Ca regulation, a $\mathrm{NO} /$ cGMP cascade is not required for cerebellar LTD induction in culture.

[Key words: long-term depression, cerebellum, nitric oxide, CGMP, cGMP-dependent protein kinase, cyclic-ADP-ribose, Purkinje neuron]

Long-term use-dependent alterations in synaptic communication are thought to underlie information storage in the brain. Experimentally, these synaptic alterations are studied as the phenomena called long-term potentiation (LTP) and long-term depression (LTD). LTP and LTD are blanket terms, each of which refers to several different processes engaged by different patterns of activity and which have varying consequences for the transmission of neuronal signals (e.g., homosynaptic LTP, associative LTP, homosynaptic LTD, heterosynaptic LTD, etc.) At a number of synapses in different brain regions, two or more of these processes can co-occur. One particular form of LTD, which has been demonstrated in the cerebellum, is a persistent, inputspecific attenuation of parallel fiber-PN synapses, which results from coactivation of parallel fiber and climbing fiber inputs to a PN at low frequency for several minutes (Ito et al., 1982). Cerebellar LTD is generally understood to have three initial requirements for induction, activation of AMPA receptors, activation of mGLURI receptors (both of which are produced by glutamate release from parallel fibers) and $\mathrm{Ca}$ influx through voltage-gated channels, which is triggered by the climbing fiber EPSP. The activation of mGLUR1 receptors results in phospholipase $\mathrm{C}$-mediated production of diacylglycerol and inositol1,4,5-trisphosphate. AMPA receptor activation exerts its effects by gating $\mathrm{Na}$ influx, which might possibly serve to slow $\mathrm{Ca}$ extrusion via a $\mathrm{Na} / \mathrm{Ca}$ exchanger. Some, or possibly all, of these signaling pathways appear to converge to produce activation of the enzyme protein kinase C (PKC), which is necessary for LTD induction. Cerebellar LTD is expressed postsynaptically as a depression of AMPA sensitivity and, at present, has not been found to have a presynaptic component (see Linden, 1994b, for review).

Recently, several studies have suggested that release of the gaseous messenger molecule nitric oxide (NO) and the consequent production of cGMP by soluble guanylate cyclase are necessary for cerebellar LTD induction. Bath application of either NOS inhibitors or an extracellular NO scavenger (hemoglobin) was shown to block LTD induction by parallel fiber/climbing 
fiber conjunctive stimulation (Shibuki and Okada, 1991) or parallel fiber/depolarization conjunctive stimulation (Crepel and Jaillard, 1990; Daniel et al., 1993). Likewise, an LTD-like phenomenon could be produced when climbing fiber stimulation was replaced by bath application of NO donor molecules or membrane permeable analogs of cGMP (Shibuki and Okada, 1991; Daniel et al., 1993). Interestingly, application of cGMP or NO donors directly to the Purkinje neuron (via a patch pipette) also resulted in depression of parallel fiber responses (Daniel et al., 1993; Hartell, 1994), while postsynaptic application of an NO synthase inhibitor did not block LTD induction (Daniel et al., 1993). In contrast, Glaum et al. (1992) found no effect of a bath-applied NO donor on parallel fiber-evoked EPSPs recorded in PNs in a similar acute slice preparation. In cultured PNs, LTD of glutamate currents was unaffected by NOS inhibitors, hemoglobin, or an NO donor (Linden and Connor, 1992).

$\Lambda$ ssigning a role in LTD induction to NO signaling is complicated by several biochemical observations. While both nNOS and endothelial NOS (eNOS) immunoreactivity and activity are found in granule cells and their parallel fibers and in basket cells, they are absent in PNs (Bredt et al., 1990; Vincent and Kimura, 1992; Dinerman et al., 1994). The presence of NOS in the cells of the inferior olive and their axons, the climbing fibers, is controversial, with some groups finding none (Bredt et al., 1990; Vincent and Kimura; 1992; Ikeda et al., 1993; Chen and AstonJones, 1994) and another finding a small amount (Southam and Garthwaite, 1993). Although PNs contain guanylate cyclase (Zwiller et al., 1981; Matsuoka et al., 1992) and cGMP-dependent protein kinase (De Camilli et al., 1984), and have detectable resting levels of cGMP (Sakaue et al., 1988), they do not significantly accumulate additional cGMP in response to application of a NO donor (de Vente et al., 1990; Southam et al., 1992). Together with the observation that LTD may be induced when climbing fiber activation is replaced by direct depolarization of the PN, these findings make it difficult to design a mechanism by which climbing fiber activation triggers NO release, and NO once released acts on PNs.

Several models have been proposed to explain NO/cGMP action in cerebellar LTD. In one, climbing fiber-evoked $\mathrm{Ca}$ influx into PN dendrites causes $\mathrm{K}$-efflux, which depolarizes adjacent parallel fiber terminals, resulting in $\mathrm{Ca}$ influx and the consequent activation of NOS in this compartment (Crepel et al., 1994). The NO produced by this stimulation activates soluble guanylate cyclase in the PN, and the resultant cGMP activates PKG which, in turn, phosphorylates proteins that contribute to attenuation of AMPA receptor function. Specifically, PKG is thought to phosphorylate G-substrate, resulting in a decrease in the activity of a phosphatase that acts upon AMPA receptors that have been previously phosphorylated by PKC (Ito and Karachot, 1992; Crepel et al., 1994). Thus, in this model, LTD induction requires the concerted activation of PKC and inhibition of a phosphatase (via PKG) to produce AMPA receptors that are suitably phosphorylated and, thereby, functionally attenuated. In a second model, NO produced as a consequence of climbing fiber activation (this model does not specify exactly how this would be accomplished) activates guanylate cyclase/cGMP/PKG in the PN dendrites, resulting in the activation of ADP-ribosyl cyclase and the production of cADPr (Berridge, 1993). cADPr has been proposed to act at the type 2 ryanodine receptor to stimulate its function of $\mathrm{Ca}$-induced $\mathrm{Ca}$ release (Galione et al., 1993). The $\mathrm{Ca}$ released in this manner is then proposed to diffuse into dendritic spines, where it exerts its effect by potentiating the acti- vation of $\mathrm{IP}_{3}$-gated $\mathrm{Ca}$ stores (Berridge, 1993). Finally, a third model proposes that there is a tonic diffusible signal originating from Bergmann glia that suppresses the induction of LTD and that this signal is blocked (in a manner that is not specified) by NO formed in the PN as a consequence of climbing fiber activation (Shibuki, 1993). The present study is designed to further evaluate the first two of these models.

\section{Materials and Methods}

nNOS null mice were obtained from a breeding colony established at Johns Hopkins University with animals produced by homologous recombination in the laboratory of M. C. Fishman (Huang et al., 1993). Both male and female mice were screened for homozygosity in the nNOS null mutation by Southern blot analysis as described (Huang et al., 1993) prior to breeding. Mouse embryonic cerebellar cultures were prepared according to the protocol of Schilling et al. (1991) and were maintained in vitro for 12-17 d. Whole-cell patch-clamp recording from PNs was done essentially as previously described (Linden and Connor, 1991). Briefly, patch electrodes were attached to PN somata and were used to apply a holding potential of $-80 \mathrm{mV}$. Iontophoresis electrodes ( $1 \mu \mathrm{m}$ tip diameter) were filled with $10 \mathrm{~mm}$ glutamate (in $10 \mathrm{~mm}$ HEPES, pH 7.2 with $\mathrm{NaOH}$ ) and were positioned $\sim 20 \mu \mathrm{m}$ away from large-caliber dendrites. Test pulses of glutamate were delivered with negative current pulses ( $850 \mathrm{nA}, 30$ to $110 \mathrm{msec}$ duration) applied at a frequency of $0.05 \mathrm{~Hz}$. Previous work has shown that currents evoked in this recording configuration are mediated almost entirely by AMPA type receptors as assessed by CNQX blockade (Linden and Connor, 1991; Linden et al., 1991). Cells were bathed in a solution that contained $\mathrm{NaCl}(140 \mathrm{mM}), \mathrm{KCl}(5 \mathrm{~mm}), \mathrm{CaCl}_{2}(2 \mathrm{~mm}), \mathrm{MgCl}_{2}(0.8 \mathrm{~mm})$, HEPES (10 mM), glucose (10 mM), tetrodotoxin $(0.0005 \mathrm{~mm})$, and picrotoxin $(0.1 \mathrm{~mm})$, adjusted to $\mathrm{pH} 7.35$ with $\mathrm{NaOH}$. The recording electrode contained $\mathrm{KCl}(140 \mathrm{~mm})$, HEPES $(10 \mathrm{~mm})$, and EGTA $(1 \mathrm{~mm})$ adjusted to $\mathrm{pH} 7.35$ with $\mathrm{KOH}$, except for experiments with combined patch-clamp and fura-2 imaging in which case EGTA was omitted and $150 \mu \mathrm{M}$ fura-2, $\mathrm{K}_{5}$-salt (Molecular Probes, Eugene, OR) was added. Patch electrodes were pulled from N51A glass and polished to yield a resistance of 3-6 M $\Omega$ Membrane currents evoked by glutamate were recorded with an Axopatch $200 \mathrm{~A}$ amplifier in resistive voltage-clamp mode and stored on a chart recorder that imposed a 0 to $30 \mathrm{~Hz}$ bandpass. Experiments were conducted at ambient room temperature.

Imaging of intracellular free Ca was accomplished by measuring the background-corrected fluorescence ratio at 337 and $384 \mathrm{~nm}$ excitation using a cooled CCD camera system. Illumination at $337 \mathrm{~nm}$ was provided by a pulsed nitrogen laser operating at $20 \mathrm{~Hz}$, and $384 \mathrm{~nm}$ was provided by a separate nitrogen-pumped laser using the dye Exalite 384 (Laser Science Inc). This light was passed through a quartz fiber optic Y-conduit to the epifluorescence train of a Zeiss Axiovert 100 equipped with a $40 \times 1.3 \mathrm{NA}$ oil-immersion objective. Emission at $505 \mathrm{~nm}$ was passed through a dichroic mirror and was focused on the chip (Thompson 7883) of a slow-scan cooled CCD camera (Photometrics CH250). Exposure times were $200 \mathrm{msec}$ per single wavelength image. Digitized images were acquired to magneto-optical disk using custom software (kindly provided by Dr. D. W. Tank) running on a Macintosh IIci microcomputer. Free calcium concentration was derived from the F337/ F384 ratio measurements using the standard relationship outlined by Grynkiewicz et al. (1985).

Protoporphyrin-IX free acid (Porphyrin Products, Logan, UT), KT5823 (Calbiochem, La Jolla, CA), and chelerythrine (LC Labs, Woburn, MA) stocks were prepared in $100 \%$ DMSO prior to dilution in external saline. Protoporphyrin-IX was used in the dark to prevent photoinactivation. 8-CPT-cGMP, Sp-cGMP-S, cGMP, Rp-8CPT-cGMP-S (BioLog, La Jolla, CA), RKRARKE peptide (Peninsula Labs, Belmont, $\mathrm{CA}$ ), and zaprinast (Sigma, St. Louis, MO) were prepared as stocks in $\mathrm{ddH}_{2} \mathrm{O}$. cADPr and 8- $\mathrm{NH}_{2}$-cADPr were a generous gift of Dr. T. Walseth and were synthesized according to his published method (Walseth and Lee, 1993). All other reagents were from Sigma.

For nNOS immunocytochemistry, cells were washed with TBS (50 $\mathrm{mm}$ Tris- $\mathrm{HCl}, \mathrm{pH} 7.4,1.5 \% \mathrm{NaCl}$ ) and fixed for $30-60 \mathrm{~min}$ at $4^{\circ} \mathrm{C}$ in $4 \%$ paraformaldehyde in a $0.1 \mathrm{M}$ phosphate buffer. The cultures were then washed with TBS, followed by permeabilization with $0.2 \%$ Triton $\mathrm{X}-100$ in TBS for $5 \mathrm{~min}$. Cultures were then blocked with $4 \%$ normal goat serum, $0.1 \%$ Triton $\mathrm{X}-100$ in TBS for $60 \mathrm{~min}$, then they were incubated with affinity-purified anti-nNOS antibodies overnight at $4^{\circ} \mathrm{C}$ 

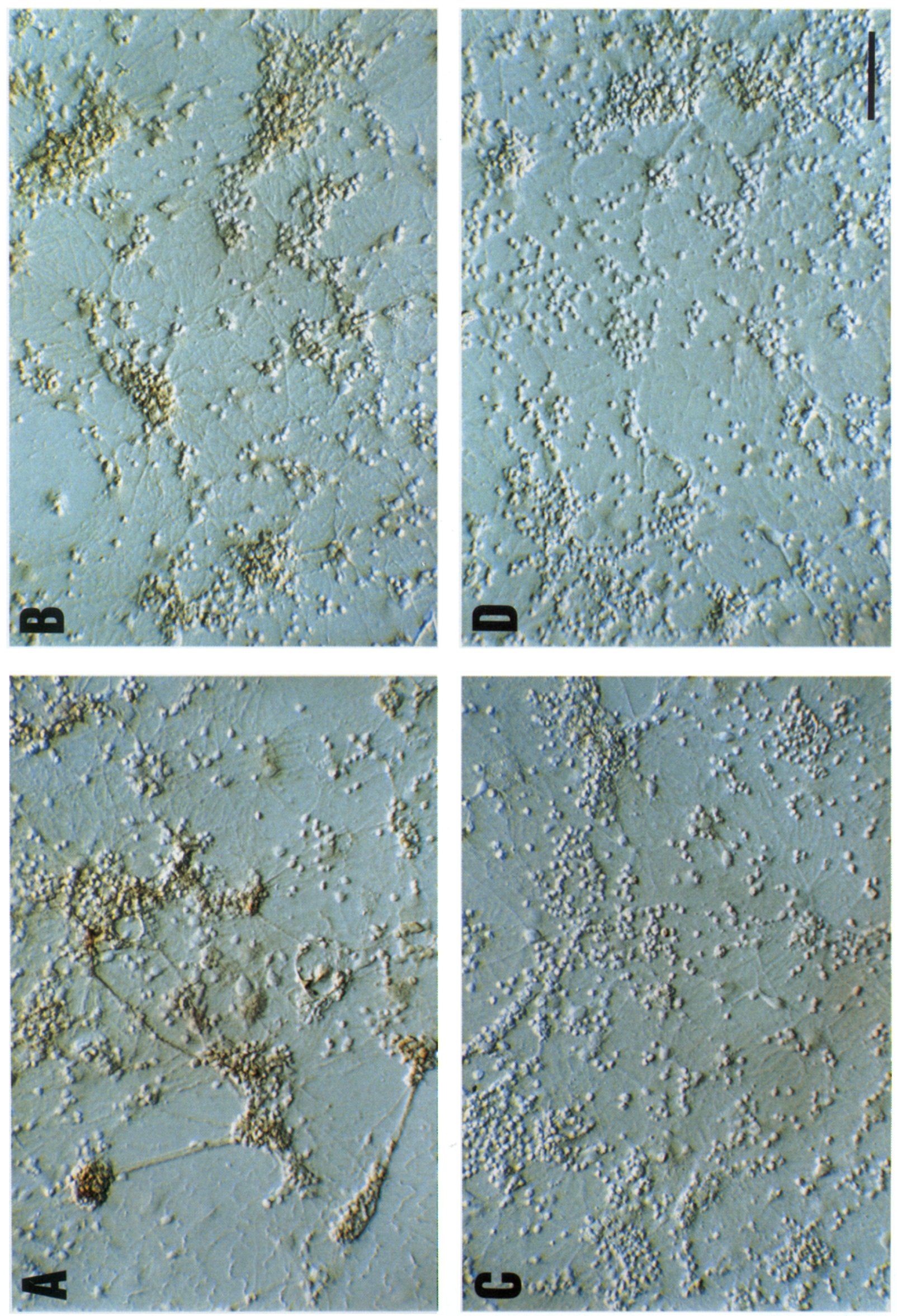

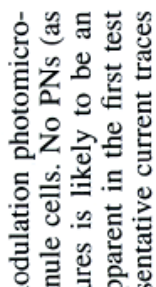

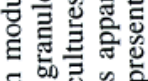

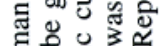

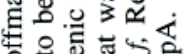

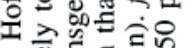

ن.

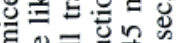

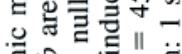

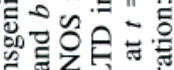

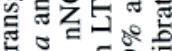

$=. \Xi . \Xi \infty)$

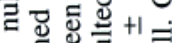

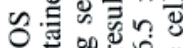

Z

엉

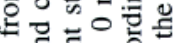

之

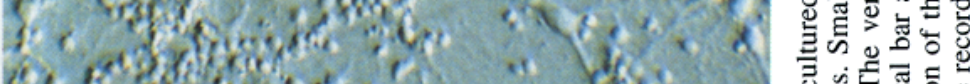

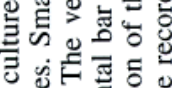

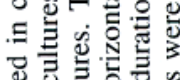

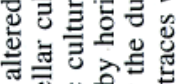

然.

的路记

ธิช

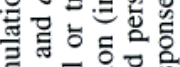

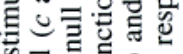

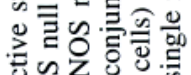

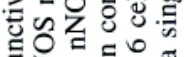

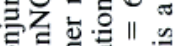

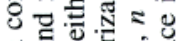

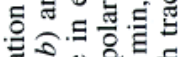

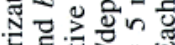

可

응 巳

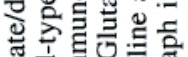

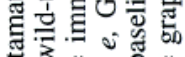

言.

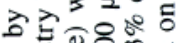

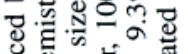

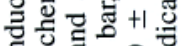

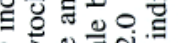

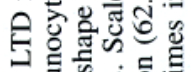

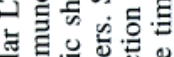

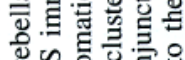

यें

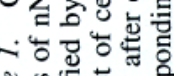

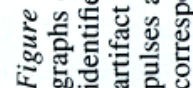




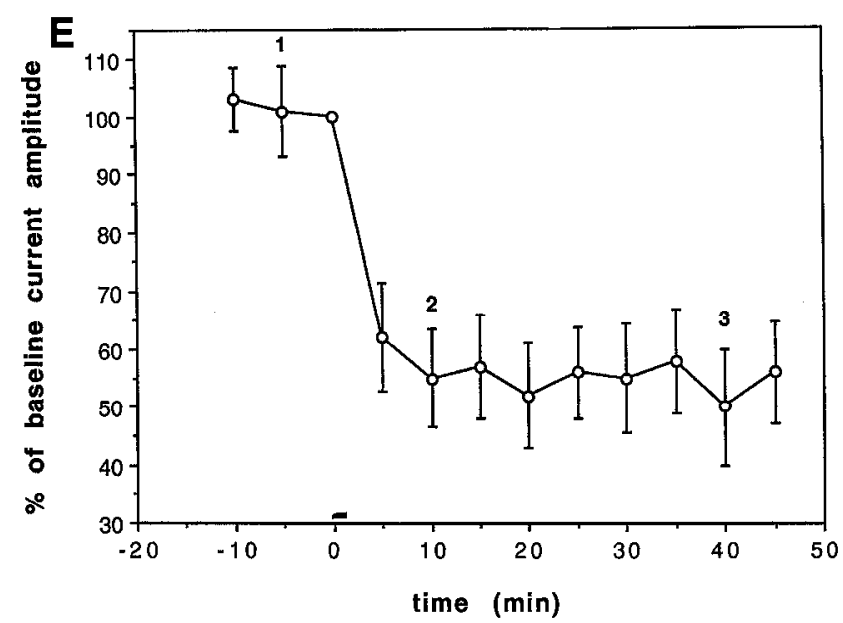

$\mathbf{F}$
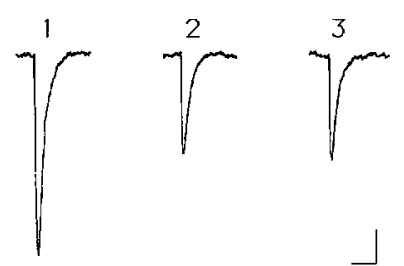

Figure 1. Continued.

(Roskams et al,, 1994). Immunostaining was visualized with biotinconjugated secondary antibody (goat anti-rabbit) and an avidin-biotinperoxidase complex (Vector Elite, Vector Laboratories) using diaminobenzidine as the substrate. Wild-type and nNOS null cultures were subjected to identical immunostaining protocols.

\section{Results}

Figure 1 illustrates an experiment in which LTD was induced in cultured PNs from nNOS null transgenic mice. After acquisition of 10 min of baseline responses, LTD was induced by pairing six successive glutamate pulses with six $3 \mathrm{sec}$ voltage steps to $+10 \mathrm{mV}$, timed so that the depolarization onset preceded the glutamate pulse by $500 \mathrm{msec}$. LTD induced in these cells was indistinguishable from that in PNs cultured from wild-type embryonic mice (compare with Fig. 4 and with examples in Linden and Connor, 1992, or Linden, 1994a). In two cases, recordings were maintained until $t=120 \mathrm{~min}$, at which point the glutamate current amplitudes were 51.0 and $62.7 \%$ of baseline, suggesting that neither an early nor a later phase of LTD was altered by nNOS knockout. In two additional PNs, LTD was induced by three, rather than six glutamate/depolarization pairings (64.9 and $58.8 \%$ of baseline current amplitude at $t=45 \mathrm{~min}$ ). nNOS immunoreactivity in these cultures was examined using an affinity purified polyclonal antiserum directed against a glutathione-Stransferase fusion protein containing amino acids $1-181$ of nNOS (Roskams et al., 1994). Note that the immunoreactivity seen in wild-type cultures, particularly in small, round clustering presumptive granule cclls, is absent in cultures from nNOS null mice (Fig. 1). No nNOS immunoreactive PNs were seen in either wild-type or nNOS null cultures. Immunoreactivity for cGMPdependent protein kinase was assessed using an antiserum directed against this protein from rat (kindly provided by Drs. U. Walter and P. De Camilli), and showed strong signal in both wild-type and nNOS null cultures (data not shown).

Figure 2 illustrates experiments designed to evaluate the effects of cGMP and cGMP analogs on glutamate-evoked inward currents applied using the same test pulses protocol as in LTD experiments. Both cGMP, which is not readily permeable to cell membranes, and 8-CPT-cGMP, which is, produced a large, transient attenuation of glutamate-evoked currents $(24.5 \pm 5.8$ and $27.3 \pm 5.1 \%$ of baseline, respectively, at $t=5 \mathrm{~min}, n=5$ ), which completely recovered to baseline values upon washout $(102.0 \pm 7.1$ and $99.3 \pm 6.3 \%$ at $t=25 \mathrm{~min})$. This effect did not appear to be dependent upon an interaction between cGMP analogs, and the glutamate test pulses as cGMP applied in the absence of glutamate test pulses (from $t=0-5 \mathrm{~min}$ ) gave rise to a similar degree of attenuation evident in the first test pulse when resumed after cGMP washout ( 23.8 and $65.6 \%$ of baseline at $t=6$ and $9 \mathrm{~min}$, respectively). To determine if the effect of cGMP analogs was being exerted internally or at the cell surface, several manipulations were performed. First, inclusion in the patch pipette saline of KT5823, a PKG inhibitor (Kase, 1988), did not block the transient depression produced by cGMP analogs. Second, two manipulations that should raise cGMP levels inside the cell, bath application of protoporphyrin-IX, a membrane permeable activator of soluble guanylate cyclase (Ignarro et al., 1992) or zaprinast, a membrane permeable inhibitor of type V cGMP phosphodiesterase (Burns et al., 1992), both failed to attenuate glutamate-evoked currents. Third, inclusion of cGMP, or its slowly metabolized analog Sp-cGMP-S, in the recording pipette saline did not give rise to a slowly developing attenuation of glutamate-current amplitude as might be expected if cGMP were acting internally.

As one model for the role of NO/cGMP signaling in cerebellar LTD induction depends upon the formation of cADPr and the consequent potentiation of $\mathrm{Ca}$-induced $\mathrm{Ca}$ release (Berridge, 1993), we investigated the effect of internally applied cADPr and externally applied NO donors on the $\mathrm{Ca}$ signals evoked by a $3 \mathrm{sec}$ depolarizing step to $+10 \mathrm{mV}$ (Fig. 3a). This depolarization protocol was chosen because it is the same one employed in our LTD induction protocol. cADPr produced several effects, a small potentiation of the basal $\mathrm{Ca}$ level recorded before depolarization, and a larger potentiation of the total $\mathrm{Ca}$ increase evoked by the depolarizing pulse caused by both an increase in peak $\mathrm{Ca}$ and a decrease in the rate of recovery to baseline. This effect was not mimicked by the NO donors sodium nitroprusside (SNP, Fig. $3 b$ ) or $S$-nitroso- $N$-acetyl-penicillamine $(100 \mu \mathrm{M}, n$ $=2$, data not shown), nor by the soluble guanylate cyclase activator, protoporphyrin-IX. Furthermore, the effect of cADPr could be completely antagonized by co-inclusion of $8-\mathrm{NH}_{2}-$ cADPr, an inhibitor of the potentiating effect of cADPr on $\mathrm{Ca}$ induced Ca release (Walseth and Lee, 1993). 8- $\mathrm{NH}_{2}-\mathrm{CADPr}$ applied alone had no effect on basal $\mathrm{Ca}$ but significantly reduced both the peak and total $\mathrm{Ca}$ increase evoked by depolarization $(75.1+4.5$ and $67.0+6.3 \%$ of baseline, respectively, $n=$ 4/group).

Finally, as one major target of NO-mediated cGMP production is $\mathrm{PKG}$, an enzyme that is highly enriched in PNs as determined by immunocytochemistry both in vivo (De Camilli et al., 1994) and in our cultures (data not shown), we chose to determine if inhibitors of PKG could alter LTD induction. Internal application of three different PKG inhibitors, KT5823, RKRARKE peptide (Glass, 1983), and Rp-8-CPT-cGMP-S (Butt et al., 1990), all failed to alter LTD induced by glutamate/depolarization conjunction (Fig. 4). In addition, internal application of $8-\mathrm{NH}_{2}-\mathrm{cADPr}$ at the same concentration that completely blocked the effect of exogenous $\operatorname{cADPr}(2 \mu \mathrm{M})$, failed to alter LTD induction. Internal application of a PKC inhibitor, cheler- 


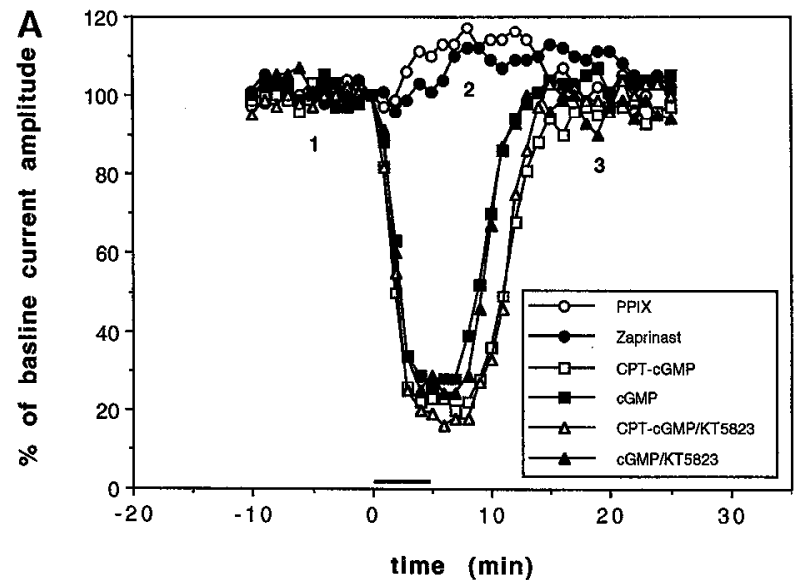

B

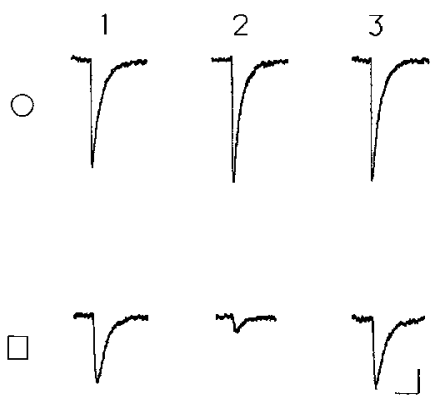

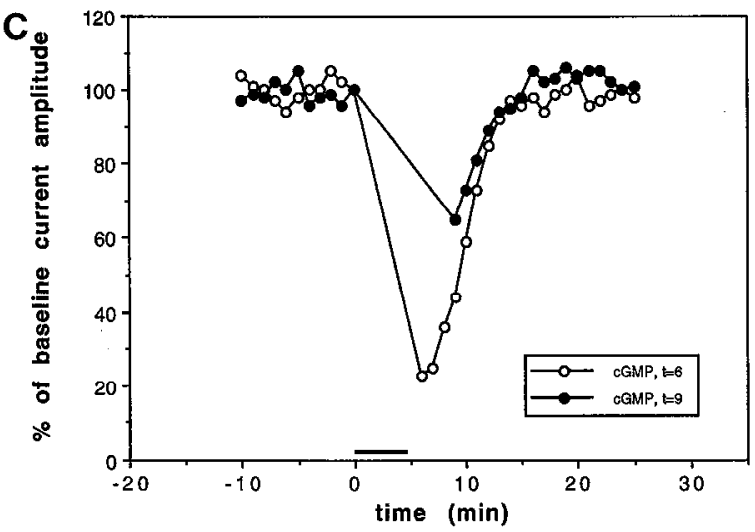

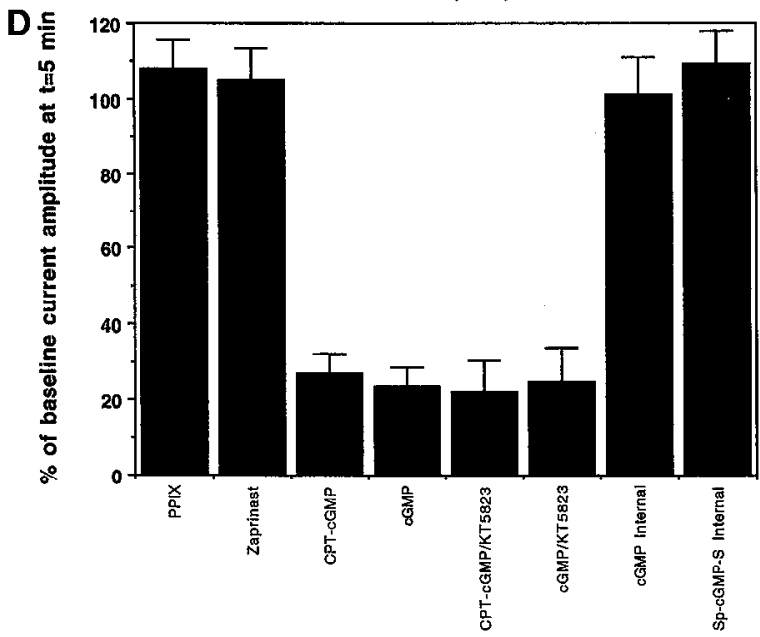

Figure 2. A transient attenuation of glutamate responses by cGMP analogs is produced by an action at the cell surface. $a$, External application of cGMP ( $1 \mathrm{mM}$, from $t=0-5 \mathrm{~min}$, indicated by the horizontal bar) or 8-CPT-cGMP $(1 \mathrm{mM})$ gave rise to a transient attenuation of glutamatecrokcd inward currents. Extcrnal application of protoporphyrin IX (PP-IX, $5 \mu \mathrm{M})$ or zaprinast $(2 \mu \mathrm{M})$ produced a small potentiation. The attenuation produced by externally applied cGMP or 8-CPT-cGMP was not blocked by inclusion of the PKG inhibitor KT5823 (1 $\mu$ M) in the recording pipette saline. Each case is illustrated by a recording from a single representative PN. $b$, Current traces from the protoporphyrin IX and 8-CPT-cGMP treatments corresponding to the times indicated on the graph in $a$. Calibration: $1 \mathrm{sec}, 60 \mathrm{pA}$. $c$, When cGMP $(1 \mathrm{~mm}, t=0-5 \mathrm{~min})$ was applied without glutamate test pulses, resumption of test pulses at either $t=6 \mathrm{~min}$ or $t=9$ min revealed a similar degree of attenuation to that seen when glutamate pulses were applied together with cGMP. $d$, Mean \pm SEM for the cases illustrated by representative single PNs in $a$. In addition, inclusion of cGMP $(0.5 \mathrm{mM})$ or Sp-cGMP-S $(0.5 \mathrm{mM})$ in the recording pipette saline did not give rise to attenuation of glutamate-evoked currents. $n=$ 5/group.

ythrine (Herbert et al., 1990) blocked LTD induction and caused glutamate/depolarization conjunction to result in a small potentiation, in a manner similar to previous experiments with other PKC inhibitors (Linden and Connor, 1991).

\section{Discussion}

The finding that LTD induced by glutamate/depolarization conjunction in PNs from nNOS knockout mice was indistinguishable from that in wild-type controls argues strongly that activation of this enzyme is not required for LTD induction in a cell culture system. Furthermore, the observation that in the wildtype mouse both NOS activity, as indicated by the diaphorase stain (Schilling et al., 1994), and nNOS immunoreactivity (Fig. 1) are present in the same cell types in the present culture system as seen in the intact cerebellar cortex in vivo suggests that the expression pattern of this enzyme is not significantly altered by our culture protocol. However, these experiments do not address the possibility of eNOS involvement in LTD induction, an issue that has arisen in consideration of a role for NO in the induction of hippocampal homosynaptic LTP (Dinerman et al., 1994).
The experiments illustrated in Figure 2 indicate that the effect of externally applied cGMP analogs on glutamate-gated inward currents is transient and due to an action at the cell surface rather than activation of a cytosolic enzyme. This might be similar to the reported effects of cAMP and its analogs at the $\mathrm{GABA}_{\mathrm{A}}$ receptor-associated ion channel of cultured hippocampal neurons, which are also transient, mediated by action at an extracellular site, and operative at millimolar concentrations (Lambert and Harrison, 1990). In addition, the present effect might underlie the transient depression of PN spiking activity recorded extracellularly in response to iontophoresis of cGMP (Hoffer et al., 1971; Siggins et al., 1976).

Is it possible that extracellular actions of cGMP on glutamate receptors might be a physiologically relevant process in the intact cerebellum? An efflux of cGMP from cerebellar slices may be detected in response to glutamate or high $\mathrm{K}$ (Tjörnhammar et al., 1986), and a microdialysis probe inserted in the cerebellum of awake, behaving rats can record an increase in extracellular cGMP stimulated by NO donors or climbing fiber activation (Vallebuona and Raiteri, 1993; Luo ct al., 1994). This cfflux is potentiated by drugs that block anion transport (probenecid, 

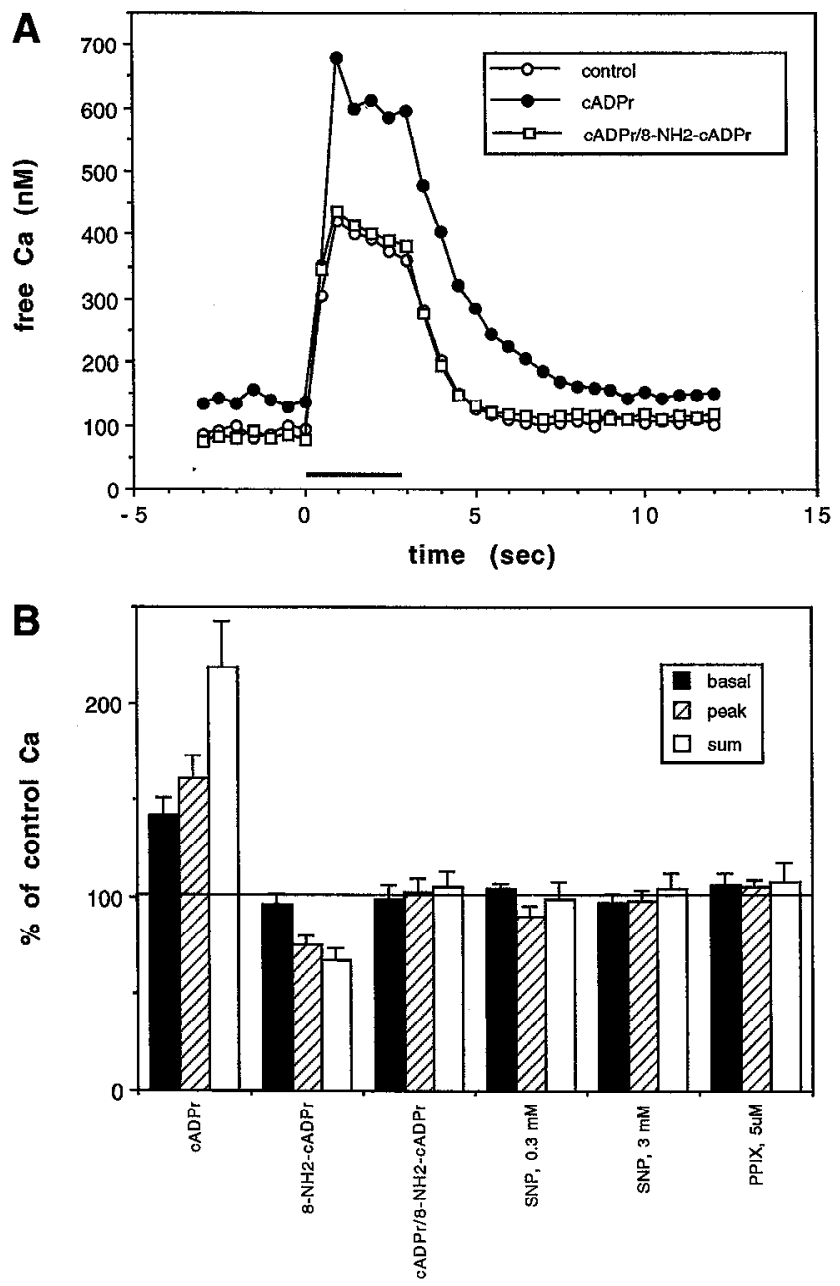

Figure 3. cADPr, but not an NO donor, produces an increase in both basal and depolarization-evoked free intracellular $\mathrm{Ca}$. $a$, The time course illustrating basal $\mathrm{Ca}$ levels and $\mathrm{Ca}$ increases evoked by a $3 \mathrm{sec}$ depolarizing voltage step from -80 to $+10 \mathrm{mV}$ with control internal saline, internal saline containing $\mathrm{cADPr}(0.5 \mu \mathrm{M})$ and internal saline containing both cADPr $(0.5 \mu \mathrm{M})$ and $8-\mathrm{NH}_{2}-\mathrm{cADPr}(2 \mu \mathrm{M})$. Each case is illustrated by a recording from a single representative PN. $b$, Mean \pm SEM for the cases illustrated by representative single PNs in $a$. Inclusion of $8-\mathrm{NH}_{2}-\mathrm{cADPr}(2 \mu \mathrm{M})$ in the recording pipette had no effect on basal $\mathrm{Ca}$, but produced a small depression of depolarization-evoked $\mathrm{Ca}$. In addition, external application of $\mathrm{Na}$ nitroprusside (SNP, 0.3 or 3 $\mathrm{mM}$ ) or protoporphyrin-IX (PP-IX, $5 \mu \mathrm{M}$ ) starting at $t=5 \mathrm{~min}$ had no effect on either basal or depolarization evoked $\mathrm{Ca}$. The basal measure was taken as the mean of the seven values recorded from $t=-3$ to 0 sec. Peak measures were taken at $t=1 \mathrm{sec}$, which was always the time point with the largest response. The sum measure represents the integrated $\mathrm{Ca}$ increase over the period $t=0-12 \mathrm{sec} . n=4 /$ group.

bromosulfophthalein) suggesting that the removal of cGMP from the extracellular space is dependent upon such a mechanism (Luo et al., 1994). However, it is not clear if the concentration of cGMP achieved extracellularly in the intact cerebellum, estimated to be approximately $10-200 \mathrm{nM}$ is ever large enough to produce the effects seen in the present study using $1 \mathrm{mM}$ cGMP. Pilot studies using extracellular application of $1 \mu \mathrm{M}$ cGMP did not produce any attenuation of glutamate-evoked currents (data not shown).

Ca-induced $\mathrm{Ca}$ release mediated by ryanodine receptors has been demonstrated in PNs as a supralinear internal Ca response evoked by depolarizing voltage-clamp commands of increasing

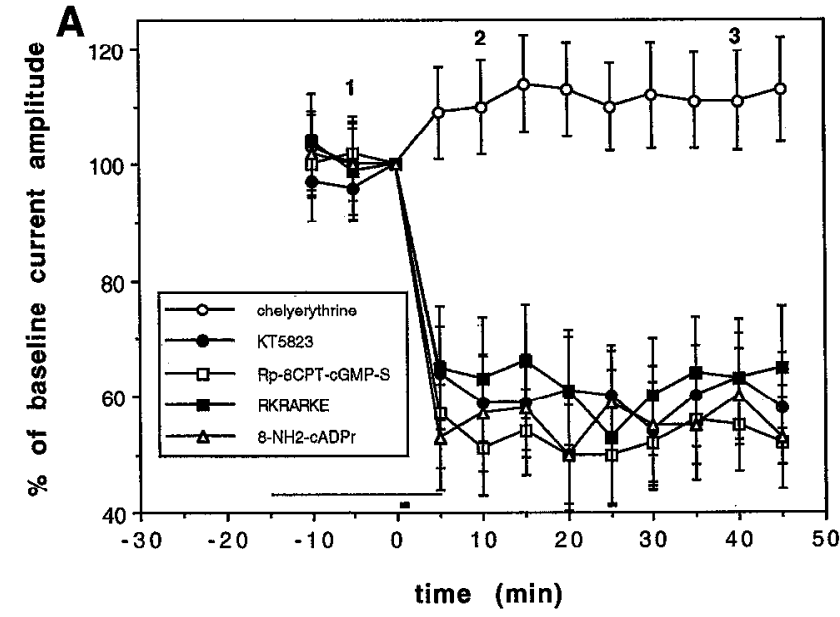

B

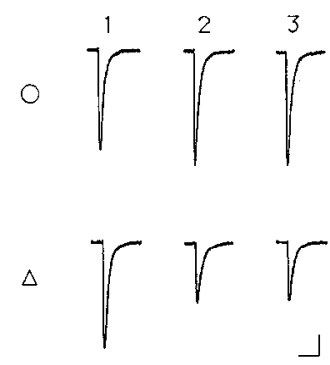

Figure 4. Inhibitors of PKG or the cADPr/ryanodine receptor interaction do not alter cerebellar LTD. $a$, Neither the PKG inhibitors KT5823 ( $1 \mu \mathrm{M})$, Rp-8CPT-cGMP-S (1 mM), RKRARKE peptide $(0.5$ $\mathrm{mM}$ ), nor the cADPr antagonist $8-\mathrm{NH}_{2}-\mathrm{cADPr}(2 \mu \mathrm{M})$ blocked LTD induced by glutamate/depolarization conjunction (indicated by horizontal bar at $t=0 \mathrm{~min}$ ) when included in the pipette saline. Inclusion of the protein kinase $C$ inhibitor chelerythrine $(10 \mu \mathrm{M})$ in the pipette saline completely blocked LTD induction. $n=6$ /group. $b$, Representative current traces. Calibration: $1 \mathrm{sec}, 40 \mathrm{pA}$.

lengths in TTX saline. The supralinear portion of the response, which was presumed to represent $\mathrm{Ca}$-induced $\mathrm{Ca}$ release (riding on top of a signal attributable to $\mathrm{Ca}$ influx), was potentiated by ryanodine and inhibited by a ryanodine receptor antagonist, ruthenium red (Llano et al., 1994). Furthermore, in bullfrog sympathetic ganglion cells it has been shown that internal application of CADPr augments depolarization-induced increases in intracellular $\mathrm{Ca}$, and that this augmentation may be blocked by ryanodine (Hua et al., 1994). The present results confirm and extend these observations by demonstrating that the $\mathrm{Ca}$ response to a prolonged depolarizing pulse in PNs may be potentiated by cADPr, presumably acting at the ryanodine receptor. Furthermore, the observation that $8-\mathrm{NH}_{2}$-cADPr blocks a portion of the depolarization-induced response indicates that CADPr may function as an endogenous modulator of Ca signaling in PNs.

Internal application of three different PKG inhibitors failed to alter LTD induction. This result is in contrast with the findings of Hartell (1994), who reported that intracellular application of KT5823 (90 nM) entirely, blocked LTD induced by parallel fiber/ climbing fiber conjunctive stimulation. Furthermore, our finding that the same dose of $8-\mathrm{NH}_{2}-\mathrm{cADPr}$ that completely blocked the cADPr-mediated increase in $\mathrm{Ca}$, failed to alter LTD induction argues that this process, while operative in cultured PNs, is not necessary for LTD induction.

Taken together with the previous observation that LTD of glu- 
tamate currents was unaffected by NOS inhibitors, hemoglobin, or an NO donor (Linden and Connor, 1992), the present findings do not support a role for any portion of a NO/cGMP/PKG cascade in the induction of cerebellar LTD in culture, as envisaged by the first two models of NO/cGMP action discussed in the Introduction. There are several potential explanations for this contradiction, none of which is completely satisfactory. One is that the difference lies in the type of stimulus used to monitor LTD. Investigations from other laboratories have used parallel fiber stimulation to monitor LTD in the cerebellar slice, while our study used glutamatc pulses applicd to PNs in culture. Therefore, if the target of NO/cGMP action were a site other than the PN dendrite (such as the parallel fiber terminal), then the effect of NO/cGMP reagents might be expected to be observed with PF stimulation used as the test stimulus but not with glutamate pulses used in the present study. However, two observations suggest that this explanation might not be correct. First, internal application of cGMP to PNs in cerebellar slices produces an LTD-like effect when combined with parallel fiber stimulation (Daniel et al., 1993; Hartell, 1994). Similarly, internal application of PKG inhibitors but not a NOS inhibitor blocked induction of LTD, suggesting a model (similar to the first two in the Introduction) in which NO formed outside of the PN activates guanylate cyclase within the PN to contribute to LTD induction in the PN in slice. Second, one report using the slice preparation showed no effect of a bath-applied NO donor on PF-cvoked EPSPs recorded in Purkinje neurons (Glaum et al., 1992).

Another explanation that was not directly addressed by the present study is that NO produced in the PN by climbing fiber stimulation blocks a tonic signal from neighboring glial cells that suppresses LTD induction. This model was suggested by the observation that treatment of cultured cerebellar slices with a gliotoxic metabolic inhibitor converted LTD from an NO-dependent (hemoglobin and L-monomethylarginine sensitive) form to an NO-independent form (Shibuki, 1993). As an explanation for the present results, this model requires that this glial suppression not be operative in cerebellar cultures. While the cultures are well endowed with glia as assessed by GFAP immunoreactivity (data not shown), it is, nonetheless, possible that the association between the relevant glial cells and the PNs is less intimate in culture than in an acute cerebellar slice. Unfortunately, the glial suppression hypothesis is not easily testable using either slice or culture preparations as gliotoxins (such as fluorocitrate) are quite nonspecific.

Finally, it has been suggested that PNs in culture fail to develop some cellular machinery that confers upon them the ability to respond to NO released from parallel fibers (Crepel et al., 1994). However, since PNs in culture from both wild-type and nNOS null mice readily demonstrate LTD, it would appear that such a developmental failure, if it, indeed, occurs, is not sufficient to prevent this form of plasticity. However, this does not mean that such a requirement could not be present in the cerebellar slice.

\section{References}

Berridge MJ (1993) A tale of two messengers. Nature 365:388-389. Bredt DS, Hwang PM, Snyder, SH (1990) Localization of nitric oxide synthase indicating a neural role for nitric oxide. Nature 347:768770.

Burns F, Rodger IW, Pyne NJ (1992) The catalytic subunit of protein kinase A triggers activation of the type $V$ cyclic GMP-specific phosphodiesterase from guinea-pig lung. Biochem J 283:487-491.
Butt E, van Bemmelen'M, Fischer L, Walter U, Jastorff B (1990) Inhibition of cGMP-dependent protein kinase by (Rp)-guanosine $3^{\prime}, 5^{\prime}$ monophosphorothioates. FEBS Lett 263:47-50.

Chen S, Aston-Jones G (1994) Cerebellar injury induces NADPH diaphorase in Purkinje and inferior olivary neurons in the rat. Exp Neurol 126:270-276.

Crepel F, Jaillard D (1990) Protein kinases, nitric oxide and long-term depression of synapses in the cerebellum. Neuroreport 1:133-136.

Crepel F, Daniel H, Hemart N, Jaillard D (1994) Mechanisms of synaptic plasticity in the cerebellum. In: Long-term potentiation, Vol 2 (Baudry M, Davis J, eds), pp 145-150. Cambridge, MA: MIT Press.

Daniel H, Hemart N, Jaillard D, Crepel F (1993) Long-term depression requires nitric oxide and guanosine $3^{\prime}-5^{\prime}$ cyclic monophosphate production in cerebellar Purkinje cells. Eur J Neurosci 5:1079-1082.

De Camilli P, MIller PE, Levitt P, Walter U, Greengard P (1984) Anatomy of cerebellar Purkinje cells in the rat determined by a specific immunohistochemical marker. Neuroscience 11:761-817.

de Vente J, Bol JGJM, Berkelmans HS, Schipper J, Steinbusch HMW (1990) Immunocytochemistry of cGMP in the cerebellum of the immature, adult, and aged rat: the involvement of nitric oxide. A micropharmacological study. Eur J Neurosci 2:845-862.

Dinerman JL, Dawson TM, Schell MJ, Snowman A, Snyder SH (1994) Endothelial nitric oxide synthase localized to hippocampal pyramidal cells: implications for synaptic plasticity. Proc Natl Acad Sci USA 91:4214-4218.

Galione A, White A, Willmott N, Turner M, Potter BVL, Watson SP (1993) cGMP mobilizes intracellular $\mathrm{Ca}^{2+}$ in sea urchin eggs by stimulating cyclic ADP-ribose synthesis. Nature 365:456-459.

Glass DB (1983) Differential responses of cGMP-dependent and cyclic AMP-dependent protein kinases to synthetic peptide inhibitors. Biochem J 213:159-164.

Glaum SR, Slater NT, Rossi DJ, Miller RJ (1992) The role of metabotropic glutamate receptors at the parallel fiber-Purkinje cell synapse. J Neurophysiol 68:1453-1462.

Grynkiewicz G, Poenie M, Tsien RY (1985) A new generation of Ca indicators with greatly improved fluorescence properties. J Biol Chem 260:3440-3450.

Hartell NA (1994) cGMP acts within cerebellar Purkinje cells to produce long-term depression via mechanisms involving PKC and PKG. Neuroreport 5:833-836.

Herbert JM, Augereau JM, Gleye J, Maffrand JP (1990) Chelerythrine is a potent and specific inhibitor of protein kinase C. Biochem Biophys Res Commun 172:993-999.

Hoffer BJ, Siggins GR, Oliver AP, Bloom FE (1971) Cyclic AMP mediation of norepinephrine synaptic inhibition in rat cerebellar cortex: a unique class of synaptic responses. Ann NY Acad Sci 185: 531-549.

Hua S-Y, Tokimasa T, Takasawa S, Furuya Y, Nohmi M, Okamoto H, Kuba K (1994) Cyclic ADP-ribose modulates $\mathrm{Ca}^{2+}$ release channels for activation by physiological $\mathrm{Ca}^{2+}$ entry in bullfrog sympathetic neurons. Neuron 12:1073-1079.

Huang PL, Dawson TM, Bredt DS, Snyder SH, Fishman MC (1993) Targeted disruption of the neuronal nitric oxide synthase gene. Cell 75:1273-1286.

Ignarro LJ, Wood KS, Wolin MS (1982) Activation of purified soluble guanylate cyclase by protoporphyrin IX. Proc Natl Acad Sci USA 79:2870-2873.

Ikeda M, Morita I, Murota S, Sekiguchi F, Yuasa 'I, Miyatake T (1993) Cerebellar nitric oxide synthase activity is reduced in nervous and Purkinje cell degeneration mutants but not in climbing fiber lesioned mice. Neurosci Lett 155:148-150.

Ito M, Karachot L (1992) Protein kinases and phosphatase inhibitors mediating long-term desensitization of glutamate receptors in cerebellar Purkinje cells. Neurosci Res 14:27-38.

Ito M, Sakurai M, Tongroach P (1982) Climbing fibre induced depression of both mossy fiber responsiveness and glutamate scnsitivity of cerebellar Purkinje cells. J Physiol (Lond) 324:113-134.

Kase H (1988) New inhibitors of protein kinases from microbial source. In: Biology of actinomycetes: proceedings of the seventh international symposium on biology of actinomycetes (Okami Y, Beppu T, Ogawara H, eds), pp 159-164. Tokyo: Japan Scientific Societies.

Lambert NA, Harrison NL (1990) Analogs of cyclic AMP decrease $\gamma$-aminobutyric acid $_{\mathrm{A}}$ receptor-mediated chloride current in cultured rat hippocampal neurons via an extracellular site. J Pharmacol Exp Ther 255:90-94. 
Linden DJ (1994a) Input-specific induction of cerebellar long-term depression does not require presynaptic alteration. Learn Mem 1:121128.

Linden DJ (1994b) Long-term synaptic depression in the mammalian brain. Neuron 12:457-472.

Linden DJ, Connor JA (1991) Participation of postsynaptic PKC in cerebellar long-term depression in culture. Science 254:1656-1659.

Linden DJ, Connor JA (1992) Long-term depression of glutamate currents in cultured cerebellar Purkinje neurons does not require nitric oxide signalling. Eur J Neurosci 4:10-15.

Linden DJ, Dickinson MH, Smeyne M, Connor JA (1991) A long-term depression of AMPA currents in cultured cerebellar Purkinje neurons. Neuron 7:81-89.

Llano I, DiPolo R, Marty A (1994) Calcium-induced calcium release in cerebellar Purkinje cells. Neuron 12:663-673.

Luo D, Leung E, Vincent SR (1994) Nitric oxide-dependent efflux of cGMP in rat cerebellar cortex: an in vivo microdialysis study. J Neurosci 14:263-271.

Matsuoka I, Giuili G, Poyard M, Stengel D, Parma J, Guellan G, Hanoune J (1992) Localization of adenylyl and guanylyl cyclase in rat brain by in situ hybridization: comparison with calmodulin mRNA distribution. J Neurosci 12:3350-3360.

Roskams AJ, Bredt DS, Dawson TM, Ronnett GV (1994) Nitric oxide mediates the formation of synaptic connections in developing and regenerating olfactory receptor neurons. Neuron 13:289-299.

Sakaue M, Kuno T, Tanaka C (1988) Novel type of monoclonal antibodies against cyclic GMP and application to immunocytochemistry of the rat brain. Jpn J Pharmacol 48:47-56.

Schilling K, Dickinson M, Connor JA, Morgan JI (1991) Electrical activity in cerebellar cultures determines Purkinje cell dendritic growth patterns. Neuron 7:891-902.
Schilling K, Schmidt HHHW, Baader SL (1994) Nitric oxide synthase expression reveals compartments of cerebellar granule cells and suggests a role for mossy fibers in their development. Neuroscience 59: 893-903.

Shibuki K (1993) Nitric oxide: a multi-functional messenger substance in cerebellar synaptic plasticity. Semin Neurosci 5:217-223.

Shibuki K, Okada D (1991) Endogenous nitric oxide release required for long-term synaptic depression in the cerebellum. Nature 349:326328 .

Siggins GR, Henriksen SJ, Landis SC (1976) Electrophysiology of Purkinje neurons in the weaver mouse: iontophoresis of neurotransmitters and cyclic nucleotides, and stimulation of the nucleus locus coeruleus. Brain Res 114:53-69.

Southam E, Garthwaite J (1993) The nitric oxide-cyclic GMP signalling pathway in rat brain. Neuropharmacology 32:1267-1277.

Southam E, Morris R, Garthwaite J (1992) Sources and targets of nitric oxide in rat cerebellum. Neurosci Lett 137:241-244.

Tjörnhammar M-L, Lazaridis G, Bartafi T (1986) Efflux of cyclic guanosine-3',5'-monophosphate from cerebellar slices stimulated by L-glutamate or high $\mathrm{K}^{+}$or $N$-methyl- $N^{\prime}$-nitroso- $N$-nitrosoguanidine. Neurosci Lett 68:95-99.

Vallebuona F, Raiteri M (1993) Monitoring of cyclic GMP during cerebellar microdialysis in freely-moving rats as an index of nitric oxide synthase activity. Neuroscience 57:577-585.

Vincent SR, Kimura H (1992) Histochemical mapping of nitric oxide synthase in the rat brain. Neuroscience 46:755-784

Walseth TF, Lee HC (1993) Synthesis and characterization of antagonists of cyclic-ADP-ribose-induced $\mathrm{Ca}^{2+}$ release. Biochim Biophys Acta 1178:235-242

Zwiller J, Ghandour MS, Revel MO, Basset P (1981) Immunohistochemical localization of guanylate cyclase in rat cerebellum. Neurosci Lett 23:31-36. 